
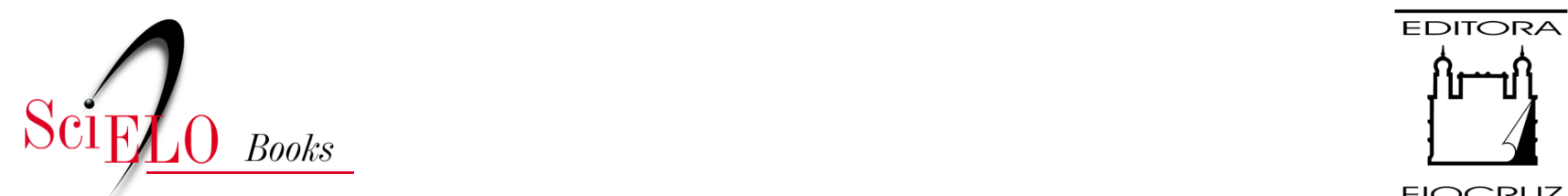

FIOCRUZ

\title{
6. Projeção das capacidades de formação de profissionais da saúde
}

\author{
Mario Roberto Dal Poz \\ Thereza Christina Varella \\ Maria Ruth dos Santos
}

\section{SciELO Books / SciELO Livros / SciELO Libros}

DAL POZ, M.R., VARELLA, T.C., and SANTOS, M.R. Projeção das capacidades de formação de profissionais da saúde. In: NORONHA, J.C., LIMA, L.D., CHORNY, A.H., DAL POZ, M.R., and GADELHA, P., eds. Brasil Saúde Amanhã: dimensões para o planejamento da atenção à saúde [online]. Rio de Janeiro: Editora FIOCRUZ, 2017, pp. 213-236. ISBN: 978-65-5708-090-0. https://doi.org/10.7476/9786557080900.0008.

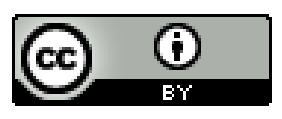

All the contents of this work, except where otherwise noted, is licensed under a Creative Commons Attribution $\underline{4.0 \text { International license. }}$

Todo o conteúdo deste trabalho, exceto quando houver ressalva, é publicado sob a licença Creative Commons Atribição 4.0.

Todo el contenido de esta obra, excepto donde se indique lo contrario, está bajo licencia de la licencia $\underline{\text { Creative }}$ Commons Reconocimento 4.0. 


\title{
PROJEÇÃO DAS CAPACIDADES DE FORMAÇÃO DE PROFISSIONAIS DA SAÚDE
}

\author{
Mario Roberto Dal Poz \\ Thereza Christina Varella \\ Maria Ruth dos Santos
}

A análise dos principais aspectos históricos e conceituais das mudanças e necessidades de qualificação técnica, conhecimento especializado e oferta de formação das profissões da saúde de nível superior tem por objetivo delinear os condicionantes, a situação atual e os cenários possíveis e prováveis das categorias de médicos, enfermeiros, farmacêuticos, dentistas e fisioterapeutas para os próximos vinte anos.

A projeção de situações prospectivas implica a adequação de um conjunto de variáveis sendo, portanto, um trabalho eivado de incertezas. Segundo Boudon (1981), cenários são imagens de futuro, ou jogos coerentes de hipóteses nos quais há um conjunto formado pela descrição de uma situação de origem e dos acontecimentos que conduzem a uma determinada posição futura no contexto de uma narrativa lógica e coerente. Os cenários têm destaque entre os instrumentos utilizados pelos estudos prospectivos, com a vantagem de que se opõem às concepções determinísticas ou fatalistas do futuro, assumindo como pressuposto que os processos de mudanças são incertos e indeterminados e que os atores sociais têm diante de si, a cada instante, alternativas múltiplas e diversas.

A ação dos homens tem potencial para influir na história e pode assumir percursos diversos de acordo com as conjunturas políticas e os condicionamentos estruturais e que, por mais racionalidade que se imponha às prospecções, ainda assim há que se levar em conta os fatos inesperados e os constrangimentos, já que é impossível ter domínio sobre todas as variáveis. Dessa forma, é necessário dispor de lucidez para compreender que nenhum cenário será exatamente como aquele apontado, uma vez que a história evolui incorporando traços de diversas possibilidades e trazendo ainda para o contexto situações inusitadas (Porto \& Régnier, 2003).

Um determinado conjunto de cenários prospectivos pode transformar-se em um quadro de referência com incertezas reduzidas para a tomada de decisões estratégicas e para a formulação de políticas, podendo ser incorporado no processo de planejamento público da força de trabalho, tendo em vista o aperfeiçoamento do exercício das ocupações e profissões na área da saúde no Brasil e o desenvolvimento de sistemas de saúde (Vianna et al., 2013).

É consenso que as profissões, em geral, sofreram profundas transformações ao longo do século $\mathrm{XX}$ influenciadas por importantes processos de mudanças na estrutura profissional das sociedades e que as profissões da saúde, em particular, não ficaram imunes a essas mudanças. Na perspectiva da 
saúde, algumas profissões surgem, outras reduzem seu âmbito de atuação, bem como outras ainda se fortalecem abrindo novas áreas funcionais na divisão do trabalho ou se adaptam às mudanças no ambiente social e político.

Do ponto de vista da organização da rede de serviços, pode-se estabelecer, seguindo critérios socioculturais, um grupo de profissões nucleares (médicos, enfermeiros, dentistas e farmacêuticos) que sustentam grande parte das atribuições do sistema de atenção e contam com representação no imaginário social. Outras que estão em processo de consolidação de seu campo de atribuições e, mesmo que regulamentadas, tanto pelo setor educacional quanto pelos órgãos disciplinares do trabalho, ainda disputam o controle de nichos de atuação (fisioterapeuta e fisiatra, psicólogo e psiquiatra/ psicanalista, nutricionista e médicos/nutrólogos, a título de exemplo). Observa-se ainda com atenção, e de forma preliminar, profissões emergentes como obstetra, sanitarista, quiroprático, optometrista, entre outros, já com graduações em curso.

No panorama da educação superior no Brasil se destaca o crescimento expressivo do ensino universitário a partir da última década do século XX, em sintonia com as mudanças introduzidas pelas Diretrizes Curriculares Nacionais (DCNs). Na sequência, é traçado um paralelo entre a formação superior em saúde e a organização e funcionamento do sistema de saúde no país com a apresentação da situação e da evolução da formação das profissões da saúde, ressaltando-se as principais tendências quantitativas observadas desde 2000. De igual forma, analisa-se a formação das profissões da saúde com base na visão de especialistas das respectivas áreas e da revisão da literatura sobre o tema. Por fim, consideram-se os possíveis cenários e tendências para as próximas décadas.

\section{Panorama da Educação Superior no Brasil}

No campo da educação, a aprovação da Lei de Diretrizes e Bases da Educação Nacional e as DCNs para os cursos de graduação da área da saúde pelo Conselho Nacional de Educação foram movimentos importantes do setor que sinalizaram a necessidade de articulação entre o processo de formação e os princípios e diretrizes do Sistema Único de Saúde (SUS) (Brasil, 1996, 2001).

As DCNs destacam a reestruturação dos cursos de graduação com a extinção dos currículos mínimos e a adoção de diretrizes curriculares específicas para cada curso. Elencam ainda responsabilidades para as instituições de ensino em relação à autonomia didático-científica, à autonomia para criar cursos e fixar os currículos e programas, recomendando que cada curso adote aquelas que melhor atendam ao perfil epidemiológico e social da comunidade.

No plano internacional, em relação às possibilidades de desenvolvimento do ensino superior, observa-se uma tendência de expansão do acesso ao ensino superior ao longo das últimas décadas. Segundo a Unesco, a segunda metade do século XX passa para a história da educação superior como o período de sua expansão mais espetacular: o número de matrículas de estudantes em escala mundial se multiplicou mais de seis vezes, de 13 milhões em 1960 a 82 milhões em 1995 (Unesco, 1998).

Para Porto e Régnier (2003), os motivos que justificam esse fenômeno são múltiplos e de distintas naturezas: crescimento no número de formandos do ensino secundário (o percentual da população mundial com mais de 25 anos que concluiu o ensino médio ou secundário passou dos 15\% em 1965 
para 26\% em 1990) (World Bank, 2000); a necessidade de aquisição de competências essenciais para enfrentar um mercado de trabalho variante e cada vez mais seletivo e excludente; as transformações no conteúdo das ocupações e nas profissões, trazendo de volta para os bancos escolares uma população adulta; as facilidades que o desenvolvimento das tecnologias de informação e comunicação apresentam para o campo do ensino em termos de aumento da capacidade de atendimento das instituições, estimulando as experiências com ensino a distância; e, finalmente, o anseio da sociedade por ascensão social mediante o acesso ao ensino superior.

No Brasil, associado à qualidade de vida e à equidade social, o acesso a níveis mais altos de ensino se coloca como um elemento estratégico para que o país possa entrar competitivamente na sociedade da informação e da inovação tecnológica. O país alcançou, em 2010, 6,3 milhões de matrículas em 29,5 mil cursos oferecidos por 2.377 instituições. Considerando toda a última década, de 2001 a 2010, o crescimento no número de matrículas foi de 110\%, como pode ser visto na Tabela 1 a seguir. "Talvez tenha sido a melhor década de acesso à educação superior, tanto em termos relativos como em absolutos - mas, sobretudo, em absolutos", disse o então ministro da Educação e, segundo o ministério, um dos fatores que explica esse crescimento é o do aumento da oferta de cursos a distância e tecnológicos, dentre outros, sendo que esse forte crescimento vem se verificando nas matrículas dos cursos noturnos. No período 2011-2012, as matrículas continuaram a crescer, atingindo o número de 7.037.688 de matrículas no ensino superior brasileiro em 2012.

Tabela 1 - Número de matrículas em cursos de graduação. Brasil - 2001-2010

\begin{tabular}{|c|c|c|c|c|c|c|c|c|c|c|c|}
\hline \multirow[t]{2}{*}{ Ano } & \multirow[t]{2}{*}{ Total } & \multicolumn{8}{|c|}{ Públicas } & \multirow[t]{2}{*}{ Privadas } & \multirow[t]{2}{*}{$\%$} \\
\hline & & Total & $\%$ & Federal & $\%$ & Estadual & $\%$ & Municipal & $\%$ & & \\
\hline 2001 & 3.036 .113 & 944.584 & 31,1 & 504.797 & 16,6 & 360.537 & 11,9 & 79.250 & 2,6 & 2.091 .529 & 68,9 \\
\hline 2002 & 3.520 .627 & 1.085 .977 & 30,8 & 543.598 & 15,4 & 437.927 & 12,4 & 104.452 & 3 & 2.434 .650 & 69,2 \\
\hline 2003 & 3.936 .933 & 1.176 .174 & 29,9 & 583.633 & 14,8 & 465.978 & 11,8 & 126.563 & 3,2 & 2.760 .759 & 70,1 \\
\hline 2004 & 4.223 .344 & 1.214 .317 & 28,8 & 592.705 & 14 & 489.529 & 11,6 & 132.083 & 3,1 & 3.009 .027 & 71,2 \\
\hline 2005 & 4.567 .798 & 1.246 .704 & 27,3 & 595.327 & 13 & 514.726 & 11,3 & 136.651 & 3 & 3.321 .094 & 72,7 \\
\hline 2006 & 4.883 .852 & 1.251 .365 & 25,6 & 607.180 & 12,4 & 502.826 & 10,3 & 141.359 & 2,9 & 3.632 .487 & 74,4 \\
\hline 2007 & 5.250 .147 & 1.335 .177 & 25,4 & 641.094 & 12,2 & 550.089 & 10,5 & 143.994 & 2,7 & 3.914 .970 & 74,6 \\
\hline 2008 & 5.808 .017 & 1.552 .953 & 26,7 & 698.319 & 12 & 710.175 & 12,2 & 144.459 & 2,5 & 4.255 .064 & 73,3 \\
\hline 2009 & 5.954 .021 & 1.523 .864 & 25,6 & 839.397 & 14,1 & 566.204 & 9,5 & 118.263 & 2 & 4.430 .157 & 74,4 \\
\hline 2010 & 6.379 .299 & 1.643 .298 & 25,8 & 938.656 & 14,7 & 601.112 & 9,4 & 103.530 & 1,6 & 4.736 .001 & 74,2 \\
\hline
\end{tabular}

Fonte: Censo da Educação Superior 2010, do Instituto Nacional de Estudos e Pesquisas Educacionais Anísio Teixeira (Inep, 2012).

Essa ampliação do número de matriculados, fortemente apoiada na expansão do setor privado de ensino, vem sendo acompanhada por um conjunto de consequências, tais como: aumento no número de vagas ociosas, especialmente entre as instituições privadas, e a persistente evasão; altas taxas de inadimplência nas instituições privadas e redução da relação candidatos/vaga nos vestibulares para 
o segmento privado e aumento dessa relação para o segmento público, dentre outras. No entanto, persistem dificuldades e estrangulamentos no âmbito do sistema brasileiro do ensino superior - como as questões da qualidade do ensino ministrado, da contínua crise nas instituições públicas e de ineficiência e/ou descontinuidades dos esquemas de financiamento. Além da expansão acelerada da graduação, outras tendências se agregam na transformação do setor do ensino superior brasileiro, tais como: interiorização do ensino; consolidação da pós-graduação; melhoria na qualificação do corpo docente e aumento da produtividade do sistema, evidenciados pelos dados dos censos do Inep vinculados ao Ministério da Educação (MEC) (Porto \& Régnier, 2003: 65-68).

\section{A Formação e o Sistema de Saúde no Brasil}

O processo de institucionalização do SUS tem sido caracterizado por intensos debates que refletem a presença de interesses contrários em relação a sua materialização, tanto como política pública alicerçada na universalidade, equidade, integralidade, participação da população e dever do Estado quanto em relação à redução dos direitos constitucionais no que concerne a seu alcance e magnitude, incidindo em sua própria legitimidade.

Alguns autores indicam os riscos para a garantia de direitos universais ao avaliarem o panorama atual do SUS, explicitando ameaças presentes no cotejo entre o projeto privatista de cuidados de saúde e o projeto da Reforma Sanitária (Viana et al., 2002; Buss \& Labra, 1995; Bahia, 2014; Ocké-Reis, 2014).

Mendes e colaboradores (2011) registram ainda a desigualdade de acesso da população aos serviços de saúde, o desafio de construção de práticas baseadas na integralidade, os dilemas para alcançar a equidade no financiamento do setor, os avanços e recuos nas experiências de controle social e a falta de articulação entre os movimentos sociais dentre algumas das muitas dificuldades a serem superadas para a manutenção do SUS.

No campo específico da força de trabalho em saúde, as desigualdades têm aumentado ao longo do tempo, como demonstrado por Sousa, Dal Poz e Carvalho (2012). Os médicos e os profissionais de enfermagem são as categorias de trabalhadores da saúde com distribuição mais heterogênea entre as áreas mínimas comparáveis (AMC). ${ }^{1}$ Segundo esse estudo, os estados mais pobres experimentam a maior escassez de profissionais da saúde (abaixo da média nacional) e apresentaram as maiores disparidades na distribuição dos médicos e pessoal de enfermagem (acima da média nacional). Nas áreas pobres, a maioria do pessoal da saúde tem menor qualificação, e a maior parte dessa desigualdade acontece em razão da diferença dentro de cada estado de quintis de pobreza e do estrato rural urbano. Eliminar as disparidades no mercado de trabalho da saúde exige políticas e intervenções em nível estadual com foco em áreas pobres e rurais.

Nesse contexto em que se encontram as políticas públicas de saúde e de educação, investir na formação dos profissionais da saúde se afigura como uma das estratégias centrais para consolidar e

\footnotetext{
${ }^{1}$ Áreas mínimas comparáveis é a ferramenta mais utilizada no intuito de driblar os problemas oriundos do processo de ampliação do número de municípios e das transformações territoriais associadas ao município originário e consiste em agrupar os dados dos novos municípios aos daqueles que os originaram.
} 
defender os interesses da sociedade que realmente atendam às necessidades de saúde colocadas pela população usuária do SUS. Além disso, aumentam as exigências para que as instituições de ensino superior rompam com o modelo de ensino fragmentado, medicalizado, individualizado e com ênfase tecnicista, e se orientem para projetos de ensino voltados para a satisfação das necessidades sociais de saúde do país. Esse conjunto de transformações mapeadas, relativas tanto à perspectiva internacional quanto ao contexto específico de desenvolvimento da formação superior em saúde no país, desdobra-se em uma série de condicionantes. A natureza da evolução dessas condições irá definir o desenho que os possíveis cenários poderão adquirir nos próximos anos.

Segundo Porto e Régnier (2003) tais condicionantes se dividem entre os que têm maior ou menor incerteza quanto a sua consolidação e as trajetórias possíveis. Os de menor incerteza, também chamados de tendências consolidadas ou invariantes, dificilmente sofrerão profundas alterações a ponto de terem seu curso afetado, embora possam assumir compassos de evolução diferenciados, segundo o cenário ou contexto. Os de maior incerteza, como as mudanças em andamento, indicam que algumas dessas mudanças podem ou não vir a se concretizar e ocupar espaço proeminente na organização e funcionamento do setor, configurando as tendências para o futuro.

Dessa forma, ao analisarmos as mudanças e necessidades de qualificação técnica, conhecimento especializado e oferta de formação das profissões da saúde de nível superior, emergem como principais tendências consolidadas ou invariantes: a demografia brasileira com base no crescimento e perfil populacional e sua distribuição no país; a incorporação tecnológica reorganizando o processo de produção em saúde; e a carga das doenças e as consequências sobre as demandas profissionais.

Segundo o documento "Indicadores sociodemográficos: prospectivos para o Brasil 1991-2030" (Unfpa \& IBGE, 2006: 111-112), a julgar pelas hipóteses implícitas nas projeções dos números representativos das variáveis demográficas, pode-se deduzir que o perfil demográfico da população ainda passará por uma longa jornada de transformações, com mudança da pirâmide etária brasileira. Ao longo do período analisado, o país experimentou ganhos significativos sobre a mortalidade e, assim, continuará transpondo barreiras para assegurar aumentos na esperança de vida ao nascer e reduções na mortalidade de crianças.

Em paralelo, e levando-se em conta o continuado declínio da fecundidade e o aumento da longevidade de sua população, o Brasil caminhará rapidamente rumo a um padrão etário cada vez mais envelhecido, com reflexos imediatos no consumo de serviços de saúde. Essas mudanças, seguramente, provocarão a necessidade de avaliações permanentes das políticas sociais voltadas para o atendimento das demandas de um contingente de adultos e idosos que crescerá de maneira veloz. Por exemplo, o contingente de 65 anos ou mais demanda até quatro vezes mais internações que a média da população (WHO, 2000).

Com o envelhecimento da população brasileira, a demanda por determinadas categorias profissionais e especialidades médicas, como geriatria, tende a aumentar. Associada ao déficit, a distribuição também é irregular, uma vez que a maior parte dos profissionais está nas regiões Sul e Sudeste do país. O Norte é onde há maior carência, seguida pelo Nordeste e Centro-Oeste. No entanto, em 2030, serão 40 milhões de idosos, o que torna crítico adotar políticas e programas específicos para 
mudar o quadro atual. Além disso, com a mudança do perfil epidemiológico e com o desenvolvimento tecnológico, o Brasil vai precisar capacitar também outros profissionais tais como fisioterapeutas, enfermeiros geriátricos, odontogeriatras, dentre outros (Dal Poz, Pierantoni \& Girardi, 2013).

Vecina Neto e Malik (2007) registram em estudo sobre assistência hospitalar que, desde o início do século XX, notadamente após a sua segunda metade, houve uma busca contínua por novas drogas, equipamentos e soluções em saúde e lembram que, na saúde, a existência da inovação não implica a substituição da tecnologia anterior. ${ }^{2}$

Nas sociedades contemporâneas, num contexto de complexidade do objeto saúde-doença-cuidado e de aceleração da produção e de produtos (resultado da disseminação de novas tecnologias como microeletrônica e informática, biotecnologia, novos materiais, química fina e novas fontes energéticas e de mudança nos padrões de competitividade dos países decorrentes dos rearranjos no sistema capitalista de produção), surgem desafios relacionados às necessidades de integração das diversas profissões no que se refere à incorporação de novas tecnologias no processo de trabalho e a reorientações na formação e nas qualificações profissionais.

A crescente disponibilidade de novas tecnologias provoca redefinição do conteúdo do trabalho, das condições de empregabilidade e reorganização do processo de produção, o que por sua vez repercute na estrutura do mercado de trabalho, com o desaparecimento de um conjunto de ocupações e o surgimento de outras, e com o consequente redimensionamento do espaço de cada uma na atenção em saúde.

Para Vecina Neto e Malik (2007) o perfil epidemiológico se constitui em um elemento presente em todos os cenários. Desde o fim do século XX, observa-se a redução da mortalidade por moléstias infectocontagiosas (a velha agenda), o aumento da mortalidade ocasionada pelas doenças crônicodegenerativas e causas externas (a nova agenda, formada pelas chamadas doenças e agravos não transmissíveis - Dant), o reaparecimento de enfermidades que faziam parte da agenda antiga (como a dengue, a tuberculose e o cólera, denominadas reemergentes) e o surgimento da "novíssima agenda", representada por enfermidades infectocontagiosas emergentes (Aids, hantaviroses, doença espongiforme humana, além de bactérias ultrarresistentes a antibióticos).

Na visão de Schmidt e colaboradores (2011), as doenças crônicas não transmissíveis (DCNT) se tornaram prioridade na área da saúde no Brasil posto que $72 \%$ das mortes ocorridas em 2007 foram atribuídas a elas. As DCNT são a principal fonte da carga de doença, e os transtornos neuropsiquiátricos detêm a maior parcela de contribuição.

Esse novo perfil de doenças, associado à potencialização de outros elementos, tende a um aumento na demanda de utilização de ações e serviços de saúde cada vez mais complexos. Os portadores de enfermidades crônico-degenerativas têm necessidade de cuidados por período mais longo que aqueles com doenças infectocontagiosas. As complicações das doenças crônico-degenerativas associadas ao aumento na faixa etária se traduzem em necessidade mais intensa de recursos tecnológicos (Vecina Neto \& Malik, 2007: 826).

${ }^{2}$ Em relação à incorporação de tecnologias, a medicina baseada em evidências e a avaliação de tecnologia têm sido propostas, mas pouco utilizadas. Há centros que fazem avaliação tecnológica, mas seus resultados, mesmo considerados acertados, nem sempre são seguidos, segundo Vecina Neto e Malik (2007: 827). 
Além das invariantes que provavelmente devem estar presentes em qualquer configuração de contexto ou cenário, o desenho para o setor irá depender da evolução de um conjunto de condicionantes. Tais reservas se referem tanto ao fortalecimento/enfraquecimento do setor com o aporte de financiamento influenciando a conformação de modelos de atenção e o estabelecimento de prioridades quanto às transformações nos marcos regulatórios profissionais e o embate em arenas políticas conformando novos arranjos no mercado de trabalho. Por exemplo, mudanças nos marcos legais passam pelo Congresso, envolvem órgãos de controle (Ministério Público e Tribunal de Contas) e o Judiciário, entre outros. Esse tipo de ação, em geral, ultrapassa os tempos dos mandatos do Executivo.

Nesse caso, o que irá definir a configuração futura do ensino superior em saúde no país serão as escolhas que os diversos agentes que partilham essa área vierem a adotar em relação às constrições externas e da sua disposição de levar adiante projetos próprios, no jogo de forças entre os atores e suas disputas de poder e conquista de espaço. Esse processo pode resultar no surgimento de novos serviços, formas de atuação etc. com transformações nos ambientes político, econômico, social, tecnológico, cultural, dentre outros. Apesar das dificuldades de previsão sobre as políticas, e elas valem inclusive para as projeções, particularmente no que diz respeito às possíveis mudanças no que queremos para 2030, a implementação dessa agenda exige o planejamento de longo prazo. O estabelecimento de projeções para mais duas décadas deverá levar em consideração as variáveis apresentadas.

\section{Situação Atual da Formação das Profissões da Saúde}

O Brasil vem atravessando nas últimas décadas um processo conjugado de modernização econômica e abertura externa com estabilidade econômica. Dentre os estrangulamentos estruturais que comprometem a competitividade sistêmica do Brasil no contexto internacional de acelerada mudança estão os baixos níveis de escolaridade e de qualificação da mão de obra e, interligado a isso, as limitações do sistema de inovação e desenvolvimento tecnológico.

Em relatório sobre educação divulgado pela Organização para a Cooperação e Desenvolvimento Econômico (OCDE) em setembro de 2012 (OECD, 2012), o Brasil está na 38ª colocação entre 40 nações quando o assunto é educação superior. Somente $11 \%$ da população entre 25 e 64 anos de idade atingiram esse patamar educacional, quando o recomendável é, ao menos, 31\%. Somando-se a isso, apenas 18\% da população brasileira entre 18 e 24 anos (IBGE, 2011) estão matriculados no ensino superior, índice inferior a Bolívia (22\%), Colômbia (23\%) e Chile (24\%).

Apesar desses índices, houve no país uma forte expansão do ensino superior a partir da década de 1990, atrelada especialmente ao setor privado e marcada por um processo de desregulação denominado por alguns autores de revolução silenciosa (Schwartzman, 2001).

Os cursos de formação das profissões na área da saúde também tiveram um incremento expressivo do número de vagas abertas, como observado na Tabela 2, determinado principalmente pelo setor privado de ensino, não obstante tenha havido expansão também nas instituições públicas (Pierantoni et al., 2012). 
Tabela 2 - Taxa de crescimento dos cursos da saúde. Brasil - 2000-2012

\begin{tabular}{|l|r|r|r|}
\hline \multicolumn{1}{|c|}{ Cursos } & 2000 & 2012 & \multicolumn{1}{c|}{$\Delta \%$} \\
\hline Biomedicina & 7 & 229 & $3171 \%$ \\
\hline Ciências biológicas & 332 & 1002 & $201 \%$ \\
\hline Educação física & 267 & 1076 & $302 \%$ \\
\hline Enfermagem & 183 & 867 & $373 \%$ \\
\hline Farmácia & 143 & 456 & $218 \%$ \\
\hline Fisioterapia & 178 & 520 & $192 \%$ \\
\hline Fonoaudiologia & 76 & 89 & $17 \%$ \\
\hline Medicina veterinária & 90 & 185 & $106 \%$ \\
\hline Medicina & 100 & 206 & $106 \%$ \\
\hline Nutrição & 99 & 366 & $269 \%$ \\
\hline Odontologia & 142 & 215 & $51 \%$ \\
\hline Psicologia & 192 & 546 & $184 \%$ \\
\hline Serviço social & 95 & 376 & $295 \%$ \\
\hline Terapia ocupacional & 37 & 59 & $59 \%$ \\
\hline
\end{tabular}

Fonte: Censo da Educação Superior 2010, do Instituto Nacional de Estudos e Pesquisas Educacionais Anísio Teixeira (Inep, 2012).

Observa-se na Tabela 3, com exceção das ciências biológicas, em todas as graduações há predomínio de cursos nas instituições privadas de ensino superior. No curso de medicina, nota-se um comportamento diferenciado nesse aspecto, pois havia em 2000 um número maior de cursos em instituições de ensino superior (IESs) públicas, quadro que se inverte em 2012. O percentual de cursos privados de psicologia decresce em 2012 em razão de um expressivo crescimento de cursos em IESs públicas. Já no curso de terapia ocupacional, o qual também registra esse decréscimo, há uma conjugação entre o crescimento de oferta pública e a diminuição de cursos em IESs privadas para explicar o fenômeno. 
Tabela 3 - Curso da área da saúde, segundo natureza jurídica. Brasil - 2000-2012

\begin{tabular}{|l|c|c|c|c|}
\hline \multicolumn{1}{|c|}{ Cursos } & \multicolumn{2}{|c|}{2000} & \multicolumn{2}{c|}{2012} \\
\hline Biomedicina & Público $\%$ & Privado\% & Público \% & Privado\% \\
\hline Ciências biológicas & 28,6 & 71,4 & 12,7 & 87,3 \\
\hline Educação física & 53,0 & 47,0 & 50,8 & 49,2 \\
\hline Enfermagem & 41,2 & 58,8 & 28,1 & 71,9 \\
\hline Farmácia & 41,0 & 59,0 & 21,3 & 78,7 \\
\hline Fisioterapia & 28,0 & 72,0 & 25,4 & 74,6 \\
\hline Fonoaudiologia & 15,2 & 84,8 & 13,7 & 86,3 \\
\hline Medicina veterinária & 14,5 & 85,5 & 25,8 & 74,2 \\
\hline Medicina & 38,9 & 61,1 & 35,7 & 64,3 \\
\hline Nutrição & 52,0 & 48,0 & 45,1 & 54,9 \\
\hline Odontologia & 28,3 & 71,7 & 21,9 & 78,1 \\
\hline Psicologia & 35,9 & 64,1 & 30,7 & 69,3 \\
\hline Serviço social & 21,9 & 78,1 & 23,3 & 76,7 \\
\hline Terapia ocupacional & 32,6 & 67,4 & 19,1 & 80,9 \\
\hline
\end{tabular}

Fonte: Censo da Educação Superior 2010, do Instituto Nacional de Estudos e Pesquisas Educacionais Anísio Teixeira (Inep, 2012).

A tendência de crescimento dos cursos é acompanhada por um expressivo aumento na oferta de vagas principalmente no setor privado. Tal quadro se reflete, por exemplo, na oferta de cursos de graduação em ciências biológicas: ainda que a rede pública disponha de um grande número de vagas e tenha observado crescimento significativo, a esfera privada ultrapassa o dobro dessa oferta. Dessa forma o percentual de crescimento das vagas é muito maior que o dos cursos em todas as graduações, com importante participação das IESs do setor privado. Entretanto, quando analisamos a taxa de ocupação dessas vagas (relação entre vagas e ingressantes), observa-se uma tendência decrescente no período de 2000 a 2012. A graduação em medicina se configura como uma excepcionalidade. Na série histórica considerada e apresentada na Tabela 4, verificou-se que o número de ingressantes supera o de vagas. Tal fato, além de ser explicado pela grande procura do curso (a relação candidato-vaga para o curso de medicina vem se mantendo no primeiro lugar no ranking de disputa por vagas na universidade), pode ser também atribuído a mandados judiciais e transferências obrigatórias, dentre outros. A fonoaudiologia e a terapia ocupacional apresentam as mais baixas taxas de ocupação de vagas. 
Tabela 4 - Taxa de ocupação de vagas das graduações da saúde. Brasil - 2000-2012

\begin{tabular}{|c|c|c|c|c|c|c|c|c|c|c|c|c|c|}
\hline \multirow[t]{2}{*}{ Cursos } & \multicolumn{13}{|c|}{ Taxa de ocupação das vagas } \\
\hline & 2000 & 2001 & 2002 & 2003 & 2004 & 2005 & 2006 & 2007 & 2008 & 2009 & 2010 & 2011 & 2012 \\
\hline Biomedicina & 95,1 & 88,5 & 90,8 & 81,1 & 73,4 & 75,5 & 58,3 & 53,4 & 51,5 & 51,4 & 47,5 & 51,3 & 59,7 \\
\hline $\begin{array}{l}\text { Ciências } \\
\text { Biológicas }\end{array}$ & 85,7 & 93,8 & 90,3 & 90,1 & 86,4 & 82,1 & 74,4 & 70,5 & 67,4 & 55,2 & 52,4 & 49,6 & 50,3 \\
\hline Educação física & 89,2 & 95,2 & 89,3 & 90,4 & 88,9 & 81,5 & 73,5 & 70,8 & 62,4 & 52,1 & 52,5 & 53,4 & 60,6 \\
\hline Enfermagem & 88,1 & 96,3 & 93,0 & 96,2 & 84,2 & 81,0 & 76,8 & 73,6 & 67,9 & 62,3 & 61,1 & 59,9 & 68,3 \\
\hline Farmácia & 94,4 & 92,7 & 92,2 & 96,2 & 90,4 & 82,8 & 80,8 & 67,9 & 62,2 & 56,9 & 59,0 & 56,6 & 64,8 \\
\hline Fisioterapia & 94,1 & 89,1 & 84,2 & 79,5 & 64,9 & 61,3 & 57,4 & 51,6 & 45,9 & 39,6 & 43,0 & 47,4 & 60,7 \\
\hline Fonoaudiologia & 61 & 66,4 & 58,7 & 5 & 45,8 & 3 & 45 & $4:$ & 33,7 & 30,9 & 26,1 & 38,0 & 50,1 \\
\hline $\begin{array}{l}\text { Medicina } \\
\text { veterinária }\end{array}$ & 88,5 & 95,8 & 89,0 & 89,6 & 85,8 & 86,6 & 90,0 & 77,2 & 69,0 & 68,9 & 74,8 & 73,6 & 94,6 \\
\hline Medicina & 109,1 & 95,9 & 108,0 & 112,0 & 104,0 & 107,8 & 116,2 & 111,7 & 112,3 & 111,7 & 112,2 & 108,4 & 112,7 \\
\hline Nutrição & 80,1 & 79,1 & 77,6 & 78,3 & 67,3 & 64,9 & 61,3 & 56,8 & 49,8 & 48,8 & 51,8 & 53,2 & 63,5 \\
\hline Odontologia & 94,5 & 93,2 & 88,9 & 80,8 & 84,3 & 80,8 & 80,5 & 77,7 & 80,6 & 76,9 & 85,7 & 89,9 & 112,0 \\
\hline Psicologia & 89,9 & 91,6 & 84,8 & 84,3 & 72,0 & 66,3 & 65,3 & 63,8 & 58,0 & 50,1 & 61,7 & 65,2 & 80,3 \\
\hline Serviço social & 90,4 & 94,0 & 90,8 & 87,9 & 83,8 & 82,5 & 79,4 & 68,3 & 59,7 & 52,7 & 58,6 & 60,4 & 61,5 \\
\hline $\begin{array}{l}\text { Terapia } \\
\text { ocupacional }\end{array}$ & 77,3 & 77,9 & 72,9 & 66,8 & 64,6 & 53,8 & 49,7 & 46,4 & 29,4 & 41,9 & 54,5 & 45,9 & 48,6 \\
\hline
\end{tabular}

Fonte: Censo da Educação Superior 2010, do Instituto Nacional de Estudos e Pesquisas Educacionais Anísio Teixeira (Inep, 2012).

Outro indicador usado na educação superior é a taxa de eficiência terminal calculada pela relação entre concluintes e ingressantes em $n$ anos de duração dos cursos. No caso da saúde utilizamos as resoluções do $\mathrm{MEC}^{3}$ que disciplinam a duração dos cursos da saúde para esse cálculo. Considerando esse indicador, a maioria das graduações da saúde apresenta baixas taxas de eficiência, com decréscimo no período de 2000 a 2012. Para essa análise consideraremos grupamentos de graduações.

As profissões tradicionais como medicina, enfermagem, odontologia e farmácia, cujas origens remontam ao Brasil Colônia, mesmo que com configurações diferenciadas das atuais, e a medicina veterinária, ligada às ações de agricultura e pecuária, organizam-se também no fim do século XIX e início do século XX. As modernas, que surgem com o processo de desenvolvimento na década de 1930, totalmente desvinculadas da saúde, como a educação física (atrelada às ações do Exército) e o serviço social, consolidam os projetos assistencialistas da época.

\footnotetext{
${ }^{3}$ Resolução n. 2, de 18 de junho de 2007 que dispõe sobre carga horária mínima e procedimentos relativos à integralização e duração dos cursos de graduação, bacharelados, na modalidade presencial e a n. 4, de 6 de abril de 2009, que dispõe sobre carga horária mínima e procedimentos relativos à integralização e duração dos cursos de graduação em biomedicina, ciências biológicas, educação física, enfermagem, farmácia, fisioterapia, fonoaudiologia, nutrição e terapia ocupacional; e bacharelados, na modalidade presencial.
} 
E há um terceiro grupo, as áreas contemporâneas, que se organizam entre as décadas de 1960 e 1970, em sua maioria regulamentadas durante o regime militar, como a psicologia, a fisioterapia, a fonoaudiologia, a terapia ocupacional, a biologia e a biomedicina.

Dentre as profissões tradicionais, o curso de medicina tem a melhor eficiência terminal: entre $92 \%$ e $96 \%$ no período analisado. A graduação em farmácia, em 2002, ostentava uma taxa de 98\%, chegando a 2012 com 53\%. O curso de enfermagem também demonstra uma tendência decrescente no período com taxas de 89\% (2002), 95\% (2007) e 59\% (2012); o de odontologia exibe comportamento semelhante com uma pequena recuperação em 2012 (72\%); educação física mantém uma taxa em torno de $60 \%$ com leve tendência decrescente; e serviço social apresentou o indicador acima de $100 \%$ em 2008, chegando a 72\% em 2012. O grupo das áreas contemporâneas revela taxas decrescentes com índices em torno de 60\% em 2012.

\section{Os Cursos Selecionados e o Enade}

Passaremos a analisar neste item o desempenho dos cursos selecionados (enfermagem, farmácia, fisioterapia, medicina e odontologia) levando em consideração o desempenho no Enade (Exame Nacional de Desempenho dos Estudantes), instituído em 2004 pela lei n 10.861 de 14 de abril deste mesmo ano como componente do Sistema Nacional de Avaliação da Educação Superior (Sinaes).

O Enade tem como objetivo aferir o desempenho dos estudantes em relação aos conteúdos programáticos previstos nas diretrizes curriculares da respectiva área de graduação, suas habilidades para ajustamento às exigências decorrentes da evolução do conhecimento e suas competências para compreender temas exteriores ao âmbito específico de sua profissão ligados à realidade brasileira e mundial e a outras áreas do conhecimento (Inep, 2012).

O desempenho dos estudantes de cada curso participante do Enade é avaliado e expresso por meio de conceitos, com base em uma escala ordenada em cinco níveis, considerando os padrões mínimos estabelecidos por especialistas das diferentes áreas do conhecimento. A seguir, na Tabela 5, expõem-se os valores escalonados.

A avaliação é realizada a cada três anos, e tomaremos como base aquelas realizadas em 2007 e 2010.

Tabela 5 - Distribuição dos conceitos

\begin{tabular}{|c|r|}
\hline Conceito & Notas finais \\
\hline 1 & 0,0 a 0,94 \\
\hline 2 & 0,95 a 1,94 \\
\hline 3 & 1,95 a 2,94 \\
\hline 4 & 2,95 a 3,94 \\
\hline 5 & 3,95 a 5,0 \\
\hline
\end{tabular}

Fonte: Enade 2010 (Inep, 2010). 


\section{Enfermagem}

Em 2010, avaliaram-se estudantes de 691 cursos, desses, 80,0\% de instituições privadas de ensino. Já em 2007 foram 540, mantendo-se, entretanto, a mesma proporcionalidade entre instituições públicas e privadas, como pode ser observado na Tabela 6.

Tabela 6 - Número de cursos de enfermagem participantes no Brasil por categoria administrativa, segundo conceitos no Enade. 2007 e 2010

\begin{tabular}{|l|r|r|r|r|r|r|r|r|r|r|r|r|r|}
\hline \multicolumn{1}{|c|}{ Conceito } & \multicolumn{2}{|c|}{1} & \multicolumn{2}{|c|}{2} & \multicolumn{2}{|c|}{3} & \multicolumn{2}{|c|}{4} & \multicolumn{3}{|c|}{5} \\
\hline Ano & 2007 & 2010 & 2007 & 2010 & 2007 & 2010 & 2007 & 2010 & 2007 & 2010 & 2007 & 2010 \\
\hline Público & 1 & 6 & 11 & 11 & 19 & 20 & 31 & 53 & 12 & 22 & 33 & 26 \\
\hline Privado & 14 & 16 & 133 & 195 & 109 & 176 & 8 & 24 & 0 & 6 & 169 & 136 \\
\hline
\end{tabular}

Fonte: Enade 2010 (Inep, 2010).

Observa-se que nos conceitos 4 e 5, que indicam uma melhor avaliação de desempenho, predominam os cursos do setor público, 40,2\% em 2007 e 54,3\% em 2010. Chama atenção que apenas $1,8 \%$ (2007) e 5,4\% (2010) dos cursos do setor privado tenham alcançado esse patamar. A maioria dos cursos do setor privado apresenta conceitos 2 e 3 (55,9\% e 67,1\%) nos anos analisados.

\section{Medicina}

No Enade, em 2007, avaliaram-se estudantes de 153 cursos. A participação de cursos do setor privado representou 58,8\% desse contingente. Em 2010 foram avaliados estudantes de 177 cursos, quando se verificou uma pequena diminuição na participação de cursos do setor privado (56,5\%), como observado na Tabela 7.

Tabela 7 - Número de cursos de medicina participantes no Brasil por categoria administrativa, segundo as Grandes Regiões e conceitos no Enade. 2007 e 2010

\begin{tabular}{|l|c|c|c|c|c|c|c|c|c|c|c|c|}
\hline Conceito & \multicolumn{2}{|c|}{1} & \multicolumn{2}{|c|}{2} & \multicolumn{2}{|c|}{3} & \multicolumn{2}{|c|}{4} & \multicolumn{3}{|c|}{5} & \multicolumn{2}{c|}{ SC } \\
\hline Ano & 2007 & 2010 & 2007 & 2010 & 2007 & 2010 & 2007 & 2010 & 2007 & 2010 & 2007 & 2010 \\
\hline Público & 4 & 1 & 10 & 1 & 12 & 11 & 17 & 31 & 8 & 24 & 10 & 9 \\
\hline Privado & 4 & 6 & 19 & 19 & 17 & 28 & 12 & 19 & 0 & 4 & 12 & 24 \\
\hline
\end{tabular}

Fonte: Enade 2010 (Inep, 2010).

Evidencia-se também na medicina uma melhor avaliação do desempenho de IES do setor público, que avançou de 2007 para 2010. Em 2007, 41\% dos cursos de instituições públicas obtiveram conceitos 4 e 5 no Enade contra 18,8\% dos cursos privados. Em 2010 o panorama melhorou: 71,4\% dos cursos públicos foram avaliados nos conceitos 4 e 5 , estando neste mesmo patamar 23\% das instituições privadas que ainda mantiveram conceitos 2 e 3 em 47\% dos cursos em 2010. 


\section{Farmácia}

Em 2010, o Enade contou com a participação de estudantes de 340 cursos, com a predominância das instituições privadas de ensino (82,1\%). No ano de 2007 avaliaram-se estudantes de 271 cursos, sendo $82,3 \%$ desse contingente representado pelo setor privado, como demonstrado na Tabela 8 .

Tabela 8 - Número de cursos de farmácia participantes no Brasil por categoria administrativa, segundo conceitos no Enade. Brasil - 2007 e 2010

\begin{tabular}{|l|r|r|r|r|r|r|r|r|r|r|r|r|r|}
\hline \multicolumn{1}{|c|}{ Conceito } & \multicolumn{2}{|c|}{1} & \multicolumn{2}{|c|}{2} & \multicolumn{2}{|c|}{3} & \multicolumn{2}{|c|}{4} & \multicolumn{2}{|c|}{ SC } \\
\hline Ano & 2007 & 2010 & 2007 & 2010 & 2007 & 2010 & 2007 & 2010 & 2007 & 2010 & 2007 & 2010 \\
\hline Público & 2 & 0 & 7 & 4 & 7 & 12 & 13 & 14 & 12 & 19 & 7 & 12 \\
\hline Privado & 24 & 5 & 84 & 43 & 38 & 120 & 2 & 43 & 1 & 4 & 74 & 64 \\
\hline
\end{tabular}

Fonte: Enade 2010 (Inep, 2010).

Como nos cursos anteriores, o desempenho dos alunos do setor público é bastante superior aos dos estudantes do setor privado. Analisando o grupamento de cursos que obteve conceitos 4 e 5 , verificamos que mais de 50\% dos estudantes de cursos do setor público tanto em 2007 quanto em 2010 estavam nesse grupamento. Apenas 1,3\% em 2007 e 16,8\% dos estudantes dos cursos do setor privado alcançaram esse patamar e mais de 50\% em 2007 e 2010 tiveram avaliação nos conceitos 2 e 3.

\section{Fisioterapia}

O Enade de fisioterapia em 2007 contou com a participação de estudantes de 399 cursos. Levandose em consideração a categoria administrativa da IES, destaca-se a predominância das instituições privadas de ensino, que concentraram quase 90\% dos cursos avaliados. Em 2010 avaliaram-se estudantes de 448 cursos, dos quais $87,3 \%$ do setor privado, como apresentado na Tabela 9.

Tabela 9 - Número de cursos de fisioterapia participantes no Brasil por categoria administrativa, segundo conceitos no Enade. Brasil - 2007 e 2010

\begin{tabular}{|l|c|c|c|c|c|c|c|c|c|c|c|c|}
\hline \multicolumn{1}{|c|}{ Conceito } & \multicolumn{2}{|c|}{1} & \multicolumn{2}{|c|}{2} & \multicolumn{2}{c|}{3} & \multicolumn{2}{c|}{4} & \multicolumn{2}{c|}{5} & \multicolumn{2}{c|}{ SC } \\
\hline Ano & 2007 & 2010 & 2007 & 2010 & 2007 & 2010 & 2007 & 2010 & 2007 & 2010 & 2007 & 2010 \\
\hline Público & 1 & 1 & 3 & 7 & 7 & 8 & 8 & 12 & 11 & 13 & 13 & 16 \\
\hline Privado & 1 & 23 & 42 & 125 & 155 & 140 & 45 & 40 & 1 & 3 & 112 & 60 \\
\hline
\end{tabular}

Fonte: Enade 2010 (Inep, 2010).

Confirma-se também nos cursos de fisioterapia uma superioridade na avaliação dos cursos de instituições públicas, dos quais 44\% obtiveram conceitos entre 4 e 5 nos dois anos analisados. Já no setor privado apenas cerca de $11 \%$ alcançou esse patamar. A maioria dos cursos deste setor obteve avaliação entre 2 e 3. 


\section{Odontologia}

Em 2007 o Enade de odontologia contou com a participação de estudantes de 173 cursos, dentre os quais 71,7\% eram de instituições privadas. Esse mesmo percentual se mantém em 2010, dos 189 cursos avaliados, como pode-se observar na Tabela 10.

Tabela 10 - Número de cursos de odontologia participantes no Brasil por categoria administrativa, segundo as Grandes Regiões e conceitos no Enade. Brasil - 2007 e 2010

\begin{tabular}{|l|c|c|c|c|c|c|c|c|c|c|c|c|}
\hline \multicolumn{1}{|c|}{ Conceito } & \multicolumn{2}{|c|}{1} & \multicolumn{2}{c|}{2} & \multicolumn{2}{c|}{3} & \multicolumn{3}{c|}{4} & \multicolumn{3}{c|}{5} \\
\hline Ano & 2007 & 2010 & 2007 & 2010 & 2007 & 2010 & 2007 & 2010 & 2007 & 2010 & 2007 & 2010 \\
\hline Público & 0 & 1 & 1 & 2 & 4 & 12 & 24 & 32 & 16 & 5 & 4 & 2 \\
\hline Privado & 5 & 4 & 31 & 36 & 56 & 58 & 11 & 14 & 1 & 4 & 20 & 19 \\
\hline
\end{tabular}

Fonte: Enade 2010 (Inep, 2010).

O desempenho superior dos estudantes avaliados nos cursos do setor púbico também é evidente na odontologia. Chama a atenção que os cursos decaíram tanto no setor público como no privado, de 2007 para 2010. Observa-se em 2007 que 81,6\% dos cursos do setor público tiveram conceitos entre 4 e 5 e 32,3\% do setor privado estiveram nesse patamar. O cenário se modifica em 2010, quando 68,5\% dos cursos do setor público obtiveram 4 e 5 e 13,3\% do setor privado alcançaram esses conceitos.

\section{As Tendências da Formação das Profissões da Saúde}

Para analisar as tendências da formação das profissões da saúde, conjugamos aspectos da conformação e estrutura da educação superior com dados secundários das graduações da saúde, refinando a análise para as categorias profissionais de médicos, enfermeiros, dentistas, farmacêuticos e fisioterapeutas. Para o alcance desse objetivo realizamos revisão sistemática da literatura sobre o tema, ouvimos e processamos opiniões de especialistas e representantes de entidades profissionais e/ou educacionais, e analisamos os dados do censo da educação superior estimando projeções da oferta educacional de profissionais para as duas décadas subsequentes.

No estabelecimento de projeções para mais duas décadas, consideraram-se as seguintes variáveis:

- A demografia brasileira com base no crescimento e perfil populacional e sua distribuição no país.

- A incorporação tecnológica criando demandas profissionais e reorganizando o processo de produção em saúde.

- A carga das doenças e as consequências sobre as demandas profissionais.

No Brasil, nas últimas décadas, a atuação dos profissionais da saúde vem passando por distintos movimentos de transição caracterizados por processos centrados na doença e na especialização, nos quais as competências profissionais convergem para a atuação na assistência à enfermidade, à lesão ou à disfunção já estabelecidas. Verifica-se também uma inflexão para o desenvolvimento de competências de caráter preventivista e promocional, voltadas para a determinação de condicionantes da qualidade de vida e saúde de indivíduos e coletividades e para sua manutenção. 
O processo de mudança de atuação dos profissionais implica revisão de competências, de saberes e habilidades, de métodos de ensino e dos múltiplos papéis que serão requeridos para desempenho de práticas ampliadas e complexas em que o cuidado e o contexto se tornam cada vez mais indissociáveis. São muitos os desafios em curso:

- desenvolver capacidades para atuar sobre os determinantes sociais da saúde na complexidade das inter-relações entre os condicionantes sociais, econômicos, ambientais, biológicos, psicológicos, subjetivos e culturais do processo saúde-doença;

- articular medidas de prevenção dos múltiplos e contínuos riscos que podem provocar agravos à saúde;

- contribuir para o desenvolvimento da governança no intuito de agir sobre os determinantes sociais da saúde com a participação na definição de responsabilidades dos atores e setores envolvidos;

- desenvolver ferramentas para as ações de promoção da saúde, de vigilância de práticas de risco e o monitoramento da situação de saúde;

- atuar em diferentes ambientes e cenários e nos diversos níveis de complexidade e de estruturação do sistema de saúde; dentre outras.

Considerando a literatura e a visão dos especialistas das áreas, foi possível identificar ao menos quatro variáveis que se articulam em diferentes aspectos apresentados na Figura 1, que influenciam na formação profissional:

Figura 1 - Variáveis e influências na formação profissional em saúde

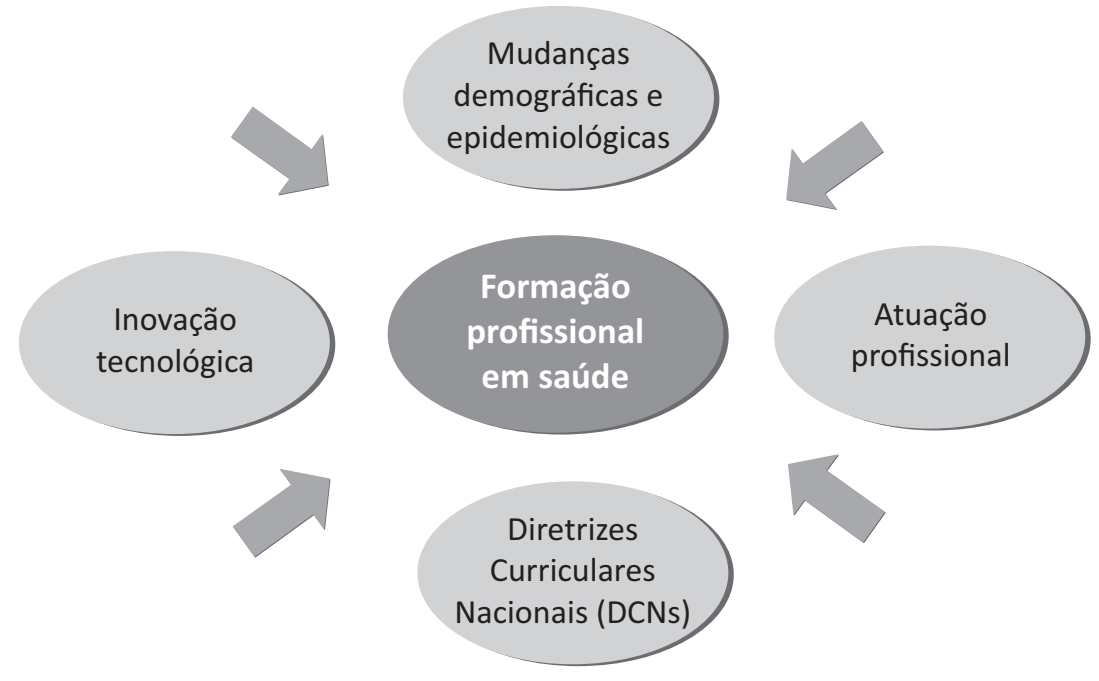

Considerando a visão dos especialistas das áreas em relação à influência das variáveis na formação profissional, observamos as tendências detalhadas a seguir:

- Atuação profissional:

» Práticas de trabalho em equipes multiprofissionais, ao passo que a formação tende a continuar segmentada. 
» Particularmente na medicina, prevalece nos espaços de formação certo desprezo pelas especialidades clínicas, traduzido pela tendência de escolha de especialidades de alta densidade tecnológica e caráter procedimental, vistas como mais bem remuneradas e de maior prestígio.

»O objeto de trabalho da fisioterapia continuará sendo o movimento humano. A responsabilidade profissional, no entanto, não se restringirá ao nível terciário da reabilitação, mas deverá se ampliar para os níveis primário e secundário.

» A fisioterapia cresce a partir da década de 1990, ampliando as suas especializações, o seu campo de atuação e redefinindo o seu status profissional. Atualmente conta com 13 especialidades regulamentadas, algumas inclusive com demandas próprias de regulamentação, como a quiropraxia.

» Em relação ao farmacêutico é necessário reafirmar que o perfil e as características desse profissional vêm sofrendo transformações substanciais neste início de século, com o resgate de suas funções básicas e originárias pertinentes aos medicamentos, com foco nos usuários desses insumos terapêuticos e uma atuação mais clínica. Para tanto, fazse necessário que os estudantes recebam uma boa formação nas disciplinas básicas de patologia, fisiologia e farmacologia.

- Inovação tecnológica:

»A semiologia vem sendo progressivamente substituída na prática clínica pelos exames de imagem e de laboratório, com imagens em três dimensões em tempo real, e repercussões claras sobre a relação custo-efetividade. Procedimentos diagnósticos de imagem e de laboratório vêm ganhando maior espaço como especialidade médica de prestígio.

»O alto turnover de conhecimentos exige movimentos de recertificação profissional, que hoje fica a cargo das sociedades de especialistas.

» As inovações tecnológicas impactam fortemente a assistência e o ensino da enfermagem, particularmente as chamadas tecnologias duras.

»Grande parte do artesanato odontológico secular necessário para os procedimentos clínicos mais corriqueiros certamente será substituído pela tecnologia digital das próximas décadas. No mínimo a dentística, a prótese e a ortodontia serão completamente reconfiguradas.

»Há uma enorme demanda por inovações na área farmacêutica, tanto no desenvolvimento e produção de medicamentos quanto nos serviços farmacêuticos diretamente dirigidos ao cuidado em saúde, demanda que impactaria tremendamente na autonomia, na soberania e na economia nacionais, mas que ainda é pouco explorada na formação profissional.

» A constante introdução de novos recursos farmacológicos e a sua diversidade abrem espaço para a atuação clínica do farmacêutico na gestão do uso de medicamentos. Nesse sentido, percebe-se um movimento nacional buscando equacionar a formação clínica farmacêutica. 
- Mudanças demográficas e epidemiológicas:

» As questões mais importantes dizem respeito à mudança de paradigma da cura para a promoção e prevenção em um contexto de envelhecimento populacional, alta prevalência de doenças crônico-degenerativas, câncer etc.

» O foco no cuidado e não na cura é claramente um produto dessas mudanças.

»Parece haver grandes diferenças na abordagem ou na forma como as escolas médicas têm priorizado ou incorporado essas mudanças. Não são disponíveis estudos suficientes.

» Há indicações de reconfiguração de currículos da enfermagem tanto para contemplar a formação de enfermeiros-obstetras que atuem na mudança do modelo de atenção à saúde da mulher e neonato, quanto para aprimorar o cuidado ao idoso, possivelmente em razão do aumento de demanda.

»O envelhecimento populacional tem como consequência para a clínica odontológica no mercado de serviços um aumento na demanda em periodontia, dentística estética, implantodontia e prótese sobre implantes.

»Para as próximas gerações, mais saudáveis (porque impactadas pelas mudanças epidemiológicas decorrentes de políticas públicas de fluoretação) e longevas, nesse mesmo mercado, apenas a demanda de periodontia deve ser mantida e aumentada. A ortodontia e a dentística estética provavelmente manterão a tendência de demanda crescente.

»O novo perfil epidemiológico, caracterizado por enfermidades relacionadas ao fazer e viver das pessoas, requer uma intervenção complexa e integral por parte do fisioterapeuta, mais voltada para uma saúde promotora do autocuidado e de ações que incorporem no cotidiano da assistência outros princípios de caráter social, formativo e educativo.

» A expansão das atividades clínicas do farmacêutico ocorreu, em parte, como resposta ao fenômeno da transição demográfica e epidemiológica observado na sociedade. A crescente morbimortalidade relativa às doenças e aos agravos não transmissíveis e à farmacoterapia repercutiu nos sistemas de saúde e exigiu um novo perfil do farmacêutico.

- Diretrizes Curriculares Nacionais (DCNs):

»Há um reconhecimento de que foram realizadas mudanças positivas para flexibilizar os desenhos curriculares conforme as realidades locais e estruturas física e pedagógica institucionais.

» Em várias áreas, como a enfermagem, incorporaram-se os conceitos de competências profissionais, regulamentaram-se os estágios e a inserção da pesquisa e produção de conhecimento como um componente importante da graduação, especialmente por meio da obrigatoriedade do trabalho de conclusão de curso.

» Entretanto, também se observam mudanças negativas, como a uniformização dos desenhos curriculares e projetos pedagógicos que, em muitos casos, passaram a ser transcrições das DCNs sem uma operacionalização cotidiana em conformidade com o proposto.

» A maior parte das orientações contidas nas diretrizes amplia conteúdos relativos a uma formação mais próxima das disciplinas da saúde coletiva, reorientando a formação do dentista, de caráter essencialmente tecnicista. 
» A fisioterapia precisa redimensionar seu objeto de intervenção, que deve aproximar-se do campo da promoção da saúde e do movimento da saúde coletiva sem abandonar suas competências concernentes à reabilitação.

»Conforme instituído nas DCNs, os cursos de fisioterapia devem estruturar-se com base nos princípios do SUS e adequar a formação dos profissionais ao perfil epidemiológico da população.

» Nesse contexto de transformações, surge o farmacêutico generalista com formação humanista, crítica e reflexiva, para atuar em todos os níveis de atenção à saúde, com base no rigor científico e intelectual, resgatando a atenção farmacêutica como atividade específica desse profissional.

» A falta de um consenso ou, minimamente, um projeto nacional para a formação/profissão farmacêutica, a tradição na formação tecnicista e biologista, as diferentes interpretações das DCNs, por vezes excessivamente simplistas e tão abrangentes que se tornam impossíveis de operacionalizar, bem como o grande crescimento do número de cursos de farmácia no setor privado, não necessariamente vinculados às necessidades sociais, ainda fazem do ensino um dos grandes desafios para a profissão farmacêutica no Brasil no atual século.

- Sensibilidade das profissões para absorver e se adaptar às mudanças:

» Parece haver certo consenso de que a escola médica ancorada na estrutura departamental disciplinar tem muita dificuldade de se mover e revisitar continuamente seus conteúdos e práticas em ritmo minimamente compatível com as mudanças.

» A farmácia apresenta uma grande capacidade de adaptação às mudanças da sociedade ou, minimamente, ao mercado de trabalho, ainda que isso possa lhe descaracterizar como profissão. Contudo, em relação ao desenvolvimento tecnológico específico da área, a questão não pode passar pelo prisma único da capacidade de adequação da profissão. Na condição de país tecnologicamente dependente e sem um projeto nacional de desenvolvimento forte, ao menos no que diz respeito à área farmacêutica, a pressão externa ao setor tem determinado a subordinação das ações em saúde - e a consequente produção de respostas em razão das necessidades de saúde de nossa população -, à lógica da potente concorrência e pressão comercial.

Observou-se na situação da formação superior das profissões da saúde no período de 2000 a 2012 algumas tendências gerais que permearam a maioria dos cursos da saúde (Inep, 2012). Em primeiro lugar tem-se uma concentração regional no Sudeste de todos os cursos da área e um expressivo crescimento fortemente pautado pela presença de instituições privadas que detêm em média $72 \%$ do total desta oferta. Essa mesma tendência é observada para o número de vagas, ingressantes e concluintes. Verifica-se também ao longo da década uma diminuição na taxa de ocupação das vagas, em especial no setor privado, a partir dos anos 2004 e 2005, exceção para o curso de medicina. A taxa de eficiência terminal dos cursos é baixa e vem decrescendo no período, o que pode ser atribuído ao aumento da evasão. Os dados utilizados para construção dos modelos de projeção para 2030 têm como fonte a série histórica de concluintes entre 1991 e 2012 para os cursos selecionados, segundo a natureza jurídica do estabelecimento de ensino, divididos em públicos e privados. 
Considerando que a adoção de hipóteses e modelos simples são mais eficientes e confiáveis, nesta análise utilizou-se um modelo de crescimento aplicando-se aos concluintes observados em 2012 uma taxa média geométrica de crescimento anual da população residente no Brasil de 1,67\% ao ano, estimada pelo IBGE (Ripsa, 2008). Na análise e aceitação dos modelos, levou-se em conta ainda que o crescimento linear das vagas e graduações só ocorreria se o mercado fosse elástico e infinito, o que não é o caso. O mercado educacional e o mercado de trabalho são relativamente inelásticos, cujo crescimento depende de algumas variáveis sociais e econômicas, como o tamanho do mercado de trabalho (empregos ou prática privada), a capacidade das famílias e/ou Estado de financiar a educação e a saúde, a existência de infraestrutura - escolas e corpo docente - e a capacidade regulatória do Estado e das próprias profissões.

Como já analisado, no período de 2003 a 2013 o número de cursos de medicina no setor privado praticamente dobrou, passando de 60 para 113. Esse crescimento bastante rápido produziu uma quantidade de egressos que sobrepujou o setor público em 2009, continuando a crescer. A proporção de concluintes em medicina no setor privado já representa praticamente $60 \%$ do total de egressos dos cursos.

Em decorrência da lei n. 12.871 de 2013 (Brasil, 2013) que institui o programa Mais Médicos, está prevista a abertura de 11.447 novas vagas de graduação em medicina até 2017. Das vagas previstas, 3,6 mil deverão ser criadas em instituições públicas e outras 7,8 mil em escolas privadas. A expectativa é a de que o número de concluintes aumente progressivamente, como mostrado no Gráfico 1.

Gráfico 1 - Concluintes do curso de medicina por natureza jurídica: projeções com modelo de crescimento linear de $1,67 \%$ anual a partir de 2012 até 2030

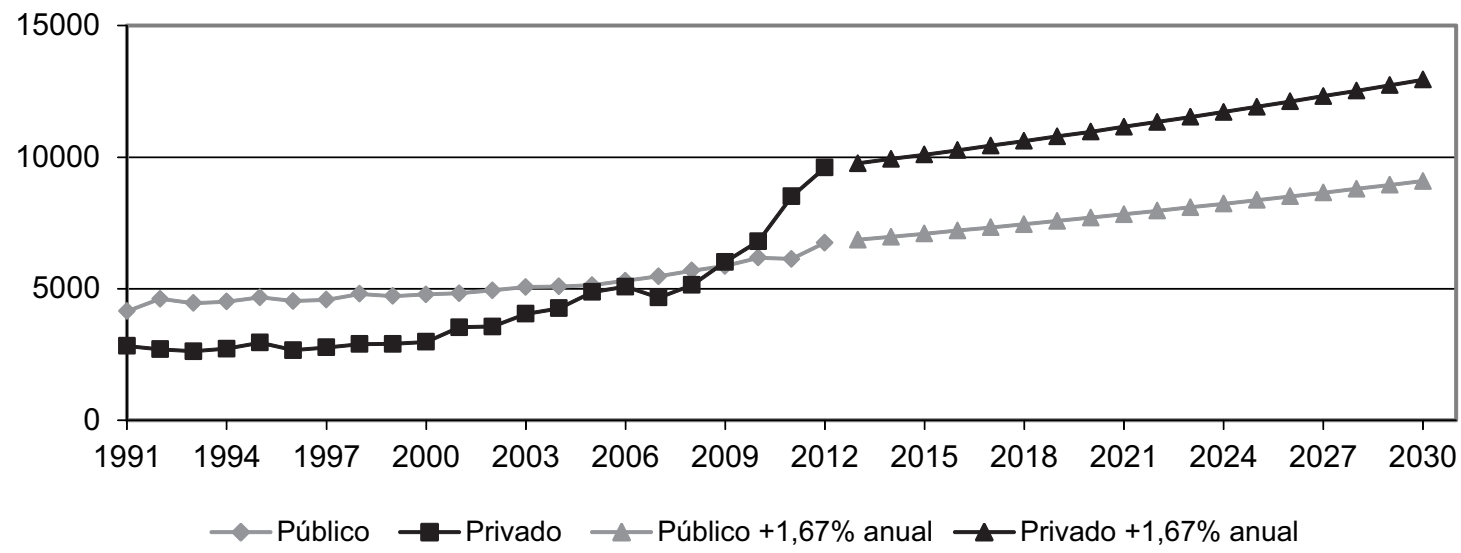

Fonte: Censo da Educação Superior 2010, do Instituto Nacional de Estudos e Pesquisas Educacionais Anísio Teixeira (Inep, 2012).

No caso da enfermagem, a taxa de ocupação das vagas vem caindo na última década, bem como se reduzindo a eficiência terminal dos cursos (ex. taxa de abandono). Assim, apesar de o número de concluintes no último ano ter sido muito alto em virtude do crescimento histórico, paralelamente há uma tendência à redução do número de vagas no setor privado, o que leva à hipótese mais provável de tendência à estabilidade no curto e médio prazo, num patamar abaixo dos quarenta mil recentes, mas provavelmente acima dos trinta mil, que se manteve estável por alguns anos. Por isso, no caso 
de concluintes de enfermagem em estabelecimentos privados, em vez de uma taxa de crescimento de 1,67\% ao ano, o cenário mais provável é de redução do número de concluintes de pelo menos $1 \%$ ao ano na projeção para 2030, como observado no Gráfico 2.

Gráfico 2 - Concluintes do curso de enfermagem por natureza jurídica: projeções com modelo de crescimento de 1,67\% anual para estabelecimentos públicos e redução de 1\% anual para estabelecimentos privados a partir de 2012 até 2030

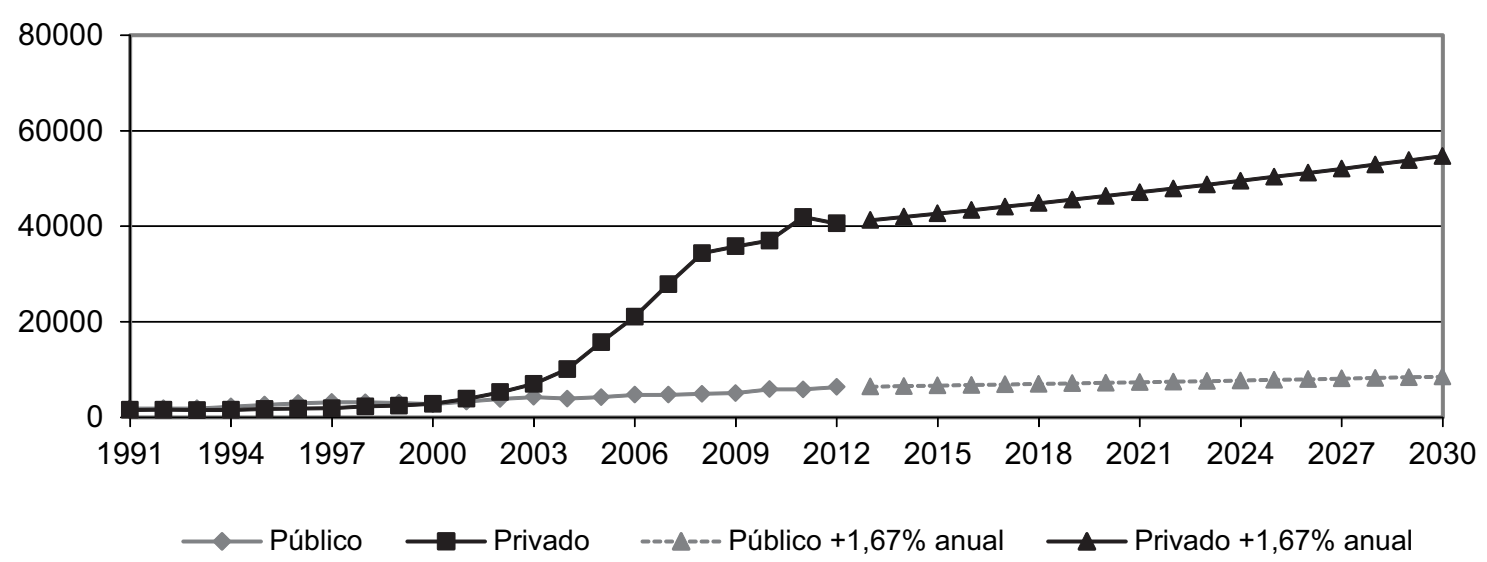

Fonte: Censo da Educação Superior 2010, do Instituto Nacional de Estudos e Pesquisas Educacionais Anísio Teixeira (Inep, 2012).

O número de concluintes de cursos de graduação em odontologia tem crescido quase que linearmente, exceto por uma aceleração entre os anos 2000 a 2003, retornando ao padrão anterior já em 2006 e se mantendo nesse padrão nos anos seguintes. Considerando o conjunto de fatores já analisados para a área de odontologia, espera-se que esse crescimento continue no mesmo padrão, que parece seguir o do crescimento demográfico, no qual o segmento privado responde por $60 \%$ dos concluintes, como pode ser observado no Gráfico 3 a seguir.

Gráfico 3 - Concluintes do curso de odontologia por natureza jurídica: projeções com modelo de crescimento linear de $1,67 \%$ anual a partir de 2012 até 2030

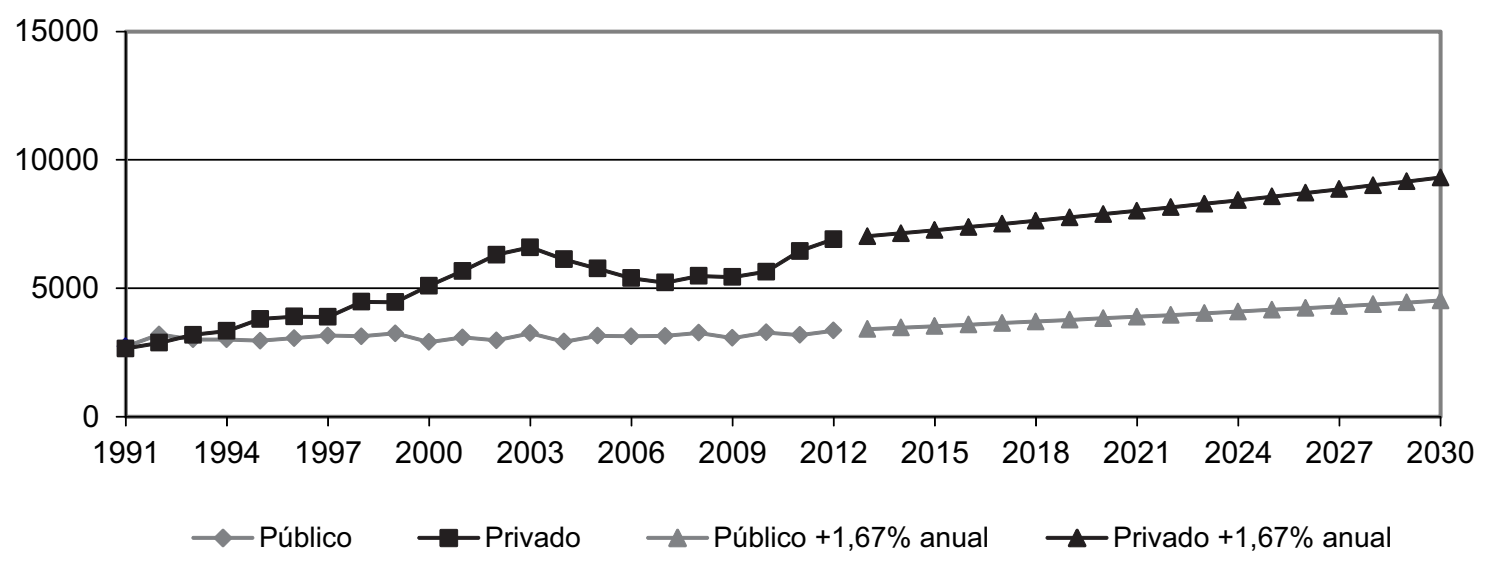

Fonte: Censo da Educação Superior 2010, do Instituto Nacional de Estudos e Pesquisas Educacionais Anísio Teixeira (Inep, 2012). 
A abertura de novos cursos de graduação em farmácia e o número de concluintes no setor privado se expandiu exponencialmente a partir do ano 2000, provavelmente respondendo à expansão acelerada do mercado de trabalho, ao passo que o setor público praticamente ficou estabilizado em torno dos 3.000 egressos por ano, tendência que deve manter-se inalterada ainda nas próximas década e meia, como apresentado no Gráfico 4.

Gráfico 4 - Concluintes do curso de farmácia por natureza jurídica: projeções com modelo de crescimento linear de $1,67 \%$ anual a partir de 2012 até 2030

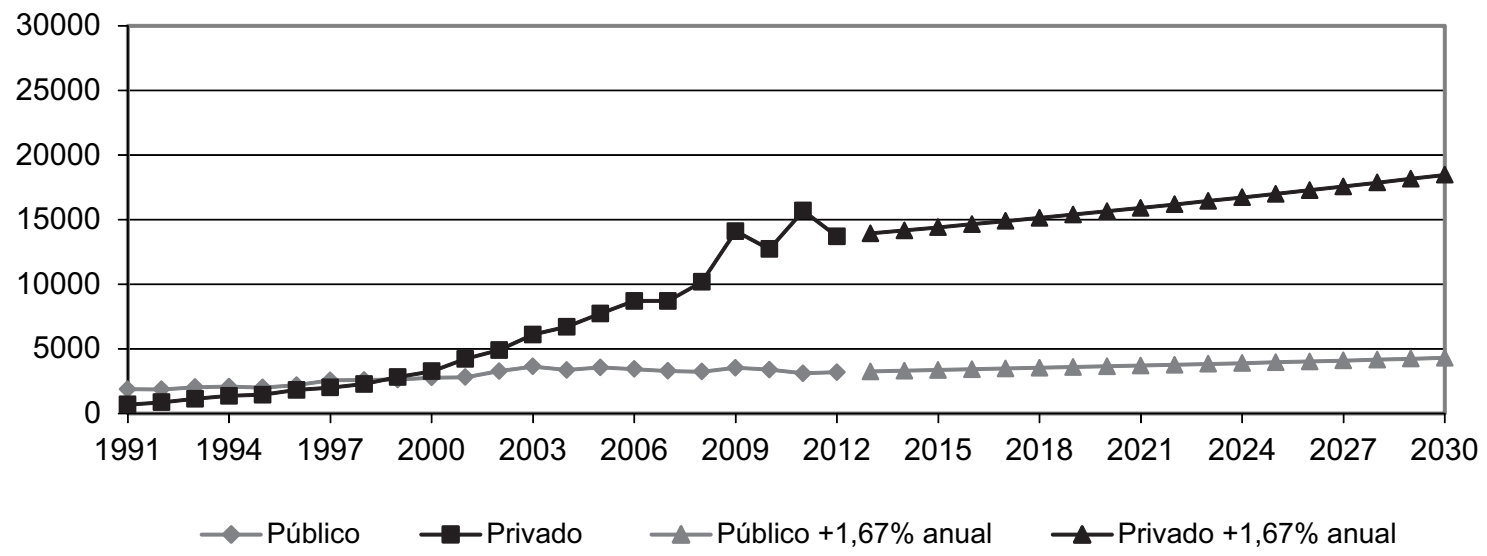

Fonte: Censo da Educação Superior 2010, do Instituto Nacional de Estudos e Pesquisas Educacionais Anísio Teixeira (Inep, 2012).

Apesar de o setor público ter dobrado sua capacidade de produção, a expansão no número de egressos dos cursos de fisioterapia ocorreu majoritariamente no segmento privado, no período de 2000 a 2010. Mesmo com uma redução em 2012, em razão da queda no número de ingressos alguns anos antes, esse quadro já se reverteu e a tendência é de retomada do crescimento, no mínimo associado ao crescimento demográfico, como visto no Gráfico 5.

Gráfico 5 - Concluintes do curso de fisioterapia, por natureza jurídica: projeções com modelo de crescimento de $1,67 \%$ anual a partir de 2012 até 2030

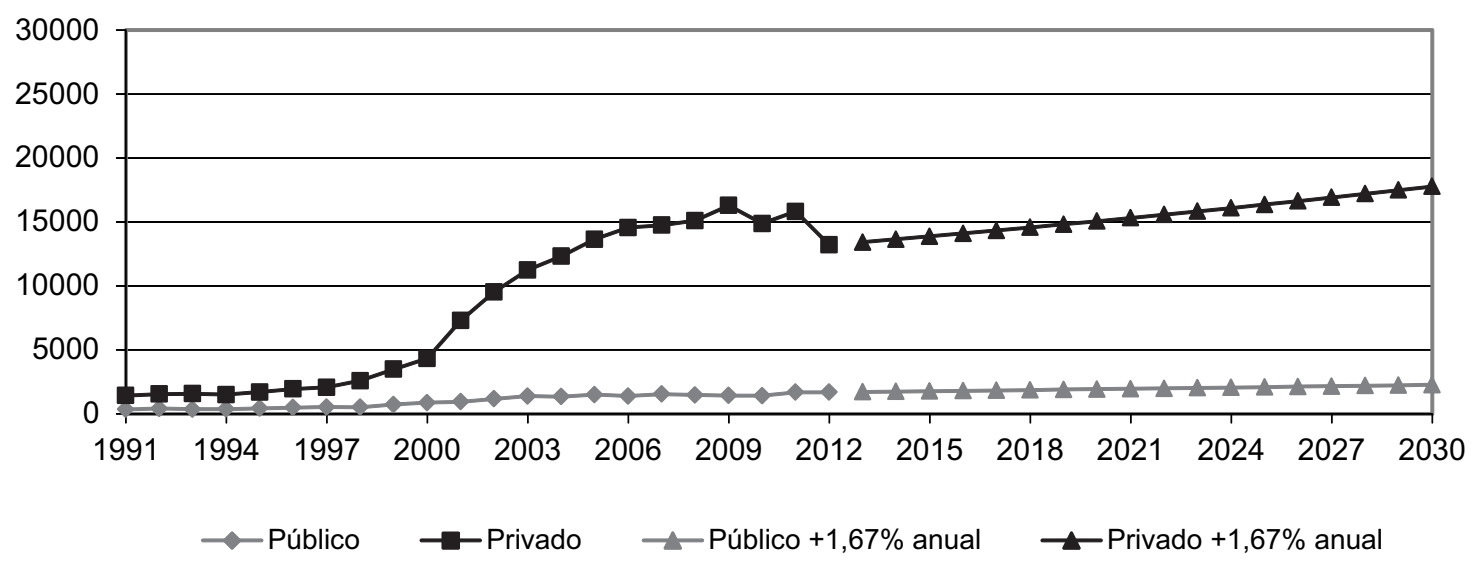

Fonte: Censo da Educação Superior 2010, do Instituto Nacional de Estudos e Pesquisas Educacionais Anísio Teixeira (Inep, 2012). 


\section{Considerações Finais}

No Brasil vivenciou-se uma forte expansão da educação superior, que se inicia em meados dos anos 1990 e toma maior impulso a partir de 2000. Tal expansão foi conformada pelas instituições de ensino superior de natureza privada e com concentração regional.

Parte da explicação desse fenômeno pode ser atribuída à flexibilização dos cursos a partir da edição das DCNs, das políticas governamentais como Fies (Fundo de Financiamento Estudantil), Prouni (Programa Universidade para Todos - programa de concessão de bolsas a instituições privadas) e à perspectiva de ascensão social via educação superior pressionando o mercado sem o respectivo incremento do ensino público.

Esse quadro se reproduziu na formação das profissões da saúde, entretanto, observa-se um esgotamento dessa tendência ascendente para quase todos os cursos, exceção da graduação em medicina que mantém uma ocupação plena de todas as vagas oferecidas e tendência de crescimento pelas políticas de fomento a expansão de cursos.

Outro aspecto a ser destacado é a superioridade da qualidade dos cursos públicos indicada pelo Enade desde sua implantação, em 2004. O percentual de cursos públicos com avaliações 4 e 5 é bem maior do que o dos cursos privados que, inversamente, mantêm um maior percentual nas avaliações de graus 2 e 3 . Esse fato poderá acarretar o fechamento de maior número de graduações e vagas do setor privado, caso o quadro não se reverta.

Em razão dos diversos fatores analisados, incluindo a lei n. 12.871 de 2013, que institui o Programa Mais Médicos, a expectativa é a de que o número de concluintes em medicina aumente progressivamente nas próximas duas décadas.

No caso da enfermagem, há uma tendência à redução do número de vagas no setor privado, o que nos conduz à hipótese mais provável de tendência à estabilidade, no curto e médio prazo, e a uma redução do número de concluintes de pelo menos 1\% ao ano na projeção para 2030.

Considerando o conjunto de fatores já analisados, a área de odontologia parece manter o mesmo ritmo de desenvolvimento do crescimento demográfico.

A tendência de crescimento em resposta à expansão acelerada do mercado de trabalho da área de farmácia deve manter-se inalterada ainda na próxima década e meia. No entanto, o número de concluintes em fisioterapia deve retomar o aumento, provavelmente associado ao crescimento demográfico.

No plano pedagógico, as DCNs cumpriram papel de fomentar mudanças na organização dos projetos político-pedagógicos com tendências às ações de cuidados que promovam a saúde das pessoas e de coletividades restringindo a focalização meramente curativa. Por outro lado, as inovações tecnológicas parecem reconfigurar áreas clássicas da clínica e semiologia por meio da adoção de diagnósticos e tratamentos cada vez mais dependentes de aparato sofisticado de tecnologias.

O discurso recorrente do trabalho em equipe e multiprofissional não foi capaz de se traduzir em práticas de ensino integradas entre as diferentes profissões da saúde, pelo contrário, mantém-se na formação o insulamento e a segmentação. 
Por fim, no plano do macrocontexto, considerando o projeto político e econômico de orientação liberal, configura-se, a médio e longo prazo, um sistema do ensino superior em saúde cada vez mais pautado pelas mudanças no próprio mercado. A tendência é de uma acentuada divisão entre poucas instituições de excelência acadêmica e tecnológica, situadas nos centros urbanos dos eixos Sul e Sudeste e um grande número de instituições com dificuldade para atender aos padrões mínimos de exigência de qualificação para o ensino e incapazes de realizar pesquisa e extensão. Em tal cenário, se forem levados a termo os processos regulatórios baseados nos mecanismos avaliativos das instituições de ensino superior, o resultado poderá ser uma reconfiguração da área, com fechamento de instituições ou novos arranjos institucionais por conglomerados e consórcios para atender às pressões do mercado.

\section{Referências}

BAHIA, L. O SUS e a agenda por resgatar, 2014. Disponível em: <http://cebes.com.br/2014/01/o-sus-e-aagenda-por-resgatar/>. Acesso em: 1 mar. 2014.

BOUDON, R. Desigualdades das Oportunidades. Brasília: Editora Universidade de Brasília, 1981. (Coleção Sociedade Moderna)

BRASIL. Senado Federal. Lei n. 9.394, de 20 dez. 1996. Estabelece as diretrizes e bases da educação nacional. Brasília, Diário Oficial da União, 1996.

BRASIL. Conselho Nacional de Saúde. Resolução n. 287/98, de 8 out. 1998. Disponível em: <www.conselho. saude.gov.br/resoluções/1998/Reso287.doc>. Acesso em: 1 mar. 2014.

BRASIL. Conselho Nacional de Educação. Câmara de Educação Superior. Resolução CNE/CES n. 3, de 7 nov. 2001. Diretrizes Curriculares Nacionais do curso de graduação em Enfermagem. Brasília, Diário Oficial da União, 2001.

BRASIL. Senado Federal. Lei n. 10.861, de 14 abr. 2004. Brasília, Diário Oficial da União, 2004. Disponível em: <www.planalto.gov.br/ccivil_03/_ato2004-2006/2004/lei/110.861.htm>. Acesso em: 1 mar. 2014.

BRASIL. Conselho Nacional de Educação. Câmara de Educação Superior. Resolução n. 2, de 18 jun. 2007. Dispõe sobre carga horária mínima e procedimentos relativos à integralização e duração dos cursos de graduação, bacharelados, na modalidade presencial. Brasília, Diário Oficial da União, n. 116, p. 6, 19 jun. 2007. Seção 1.

BRASIL. Conselho Nacional de Educação. Câmara de Educação Superior. Resolução n. 4, de 6 abr. 2009. Dispõe sobre carga horária mínima e procedimentos relativos à integralização e duração dos cursos de graduação em Biomedicina, Ciências Biológicas, Educação Física, Enfermagem, Farmácia, Fisioterapia, Fonoaudiologia, Nutrição e Terapia Ocupacional, bacharelados, na modalidade presencial. Brasília, Diário Oficial da União, n. 66, p. 27, 7 abr. 2009.

BRASIL. Senado Federal. Lei n. 12.871, de 22 out. 2013. Brasília, Diário Oficial da União, 2013. Disponível em: <www.planalto.gov.br/ccivil_03/_ato2011-2014/2013/Lei/L12871.htm>. Acesso em: 01 mar. 2014.

BUSS, P. M. \& LABRA, M. E. (Orgs.). Sistemas de Saúde Continuidades e Mudanças: Argentina, Brasil, Chile, Espanha, Estados Unidos, México e Quebec. Rio de Janeiro: Editora Fiocruz, 1995.

DAL POZ, M. R.; PIERANTONI, C. R. \& GIRARDI, S. Formação, mercado de trabalho e regulação da força de trabalho em saúde no Brasil. In: GADELHA, P.; CARVALHO, J. N. \& PEREIRA, T. R. A Saúde no Brasil em 2030: diretrizes para a prospecção estratégica do sistema de saúde brasileiro. Rio de Janeiro: Fiocruz, Ipea, Ministério da Saúde, Secretaria de Assuntos Estratégicos da Presidência da República, 2013.

FUNDO DE POPULAÇÃO DAS NAÇÕES UNIDAS (UNFPA) \& INSTITUTO BRASILEIRO DE GEOGRAFIA E ESTATISTICA (IBGE). Indicadores Sociodemográficos: prospectivos para o Brasil 1991-2030. São Paulo: ArbeitFactor, 2006. Disponível em: <www.ibge.gov.br/home/estatistica/populacao/projecao_da_populacao/publicacao_UNFPA. pdf $>$. Acesso em: 13 jan. 2014. 
INSTITUTO BRASILEIRO DE GEOGRAFIA E ESTATISTICA (IBGE). Pesquisa nacional por amostra de domicílios (Pnad). Rio de Janeiro, v. 31, p.1-135, 2011. ISSN 0101-6822. Disponível em: < http://biblioteca.ibge.gov.br/ visualizacao/periodicos/59/pnad_2013_v33_br.pdf> Acesso em: 13 jan. 2014.

INSTITUTO NACIONAL DE ESTUDOS E PESQUISAS EDUCACIONAIS ANÍSIO TEIXEIRA (INEP). Exame Nacional de Desempenho de Estudantes (Enade), 2010. Disponível em: < http://enadeies.inep.gov.br/enadeles/ enadeResultado >. Acesso em: 1 mar. 2014.

INSTITUTO NACIONAL DE ESTUDOS E PESQUISAS EDUCACIONAIS ANÍSIO TEIXEIRA (INEP). Censo da Educação Superior 2010, 2012. Disponível em: <http://portal.inep.gov.br/superior-censosuperior>. Acesso em: 12 jan. 2014.

MENDES, J. M. R. et al. Gestão na saúde: da Reforma Sanitária às ameaças de desmonte do SUS. Textos \& Contextos, 10(2): 331-344, 2011.

OCKÉ-REIS, C. O. Ciclo Eleitoral e Financiamento da Saúde: o caso dos subsídios. Rio de Janeiro: Cebes, 2014. Disponível em: < http://cebes.com.br/2014/02/ciclo-eleitoral-e-financiamento-da-saude-o-caso-dos-subsidios/> . Acesso em: 22 maio 2004.

ORGANISATION FOR ECONOMIC CO-OPERATION AND DEVELOPMENT (OECD). Education at a Glance 2012: highlights, OECD publishing, 2012. Disponível em: <http://dx.doi.org/10.1787/eag_highlights-2012-en> . Acesso em: 13 jan. 2014.

ORGANIZAÇÃO DAS NAÇÕES UNIDAS PARA A EDUCAÇÃO, A CIÊNCIA E A CULTURA (UNESCO). Declaração Mundial sobre o Ensino Superior no Século XXI: visão e ações. Paris, 1998. Disponível em: < www.direitoshumanos.usp.br/index.php/Direito-aEduca\%C3\%A7\%C3\%A3o/declaracao-mundial-sobre-educacao-superior-noseculo-xxi-visao-e-acao.html> Acesso em: 12 jan. 2014.

PIERANTONI, C. R. et al. Graduações em Saúde no Brasil: 2000 - 2010. v. 1. 1. ed. Rio de Janeiro: Cepesc, 2012.

PORTO, C. \& RÉGNIER, K. O Ensino Superior no Mundo e no Brasil - Condicionantes, Tendências e Cenários para o Horizonte 2003-2025: uma abordagem exploratória. Brasília: MEC, 2003. Disponível em: <http://portal.mec.gov. $\mathrm{br} / \mathrm{sesu} /$ arquivos/pdf/ensinosuperiormundobrasiltendenciascenarios2003-2025.pdf $>$. Acesso em: 22 maio 2014.

REDE INTERAGENCIAL DE INFORMAÇÃO PARA A SAÚDE (RIPSA). Indicadores Básicos para a Saúde no Brasil: conceitos e aplicações. 2. ed. Brasília: Organização Pan-Americana da Saúde, 2008. Disponível em: <http:// tabnet.datasus.gov.br/tabdata/livroidb/2ed/CapituloA.pdf>. Acesso em: 18 maio 2014.

SCHMIDT, M. I. et al. Doenças crônicas não transmissíveis no Brasil: carga e desafios atuais. The Lancet, 377(9.781): 1.949-1.961, 2011. (Série Saúde no Brasil, 4)

SCHWAZTZMAN, S. A Revolução Silenciosa do Ensino Superior. In: DURHAM, E. \& SAMPAIO, H. (Orgs.). O Ensino Superior em Transformação. São Paulo: Núcleo de Pesquisas sobre Ensino Superior/USP, 2001.

SOUSA, A.; DAL POZ, M. R. \& CARVALHO, C. L. Monitoring inequalities in the health workforce: the case study of Brazil 1991-2005. PlosOne, 7(3): 1-7, 2012.

VECINA NETO, G. \& MALIK, A. M. Tendências na assistência hospitalar. Ciência \& Saúde Coletiva, 12(4): 825-839, 2007.

VIANA, A. L. et al. Mudanças Significativas no processo de descentralização do sistema de saúde no Brasil. Cadernos de Saúde Pública, 18: 139-150, 2002.

VIANNA, C. M. M. et al. Modelos econométricos de estimativa da força de trabalho: uma revisão integrativa da literatura. Physis, 23: 925-950, 2013.

WORLD BANK. Higher Education in Developing Countries: peril and promise. Washington: The Task Force on Higher Education Society, 2000.

WORLD HEALTH ORGANIZATION (WHO). The World Report 2000. Health systems: improving performance. Geneva: WHO, 2000. 